\title{
Thinking Outside the Box: Moving the Respiratory Care Profession Beyond the Hospital Walls
}

\author{
Timothy R Myers MBA RRT-NPS FAARC
}

\author{
Introduction \\ Healthcare Climate and Reform \\ Extending the Continuum: Outside the Hospital Walls \\ Respiratory Care: Past and Present \\ The Future of Respiratory Care \\ Summary
}

\begin{abstract}
For centuries, hospitals have served as the cornerstone of the United States healthcare system. Just like the majority of the general population, the respiratory care profession was born inside the hospital walls, just over 6 decades ago. While the knowledge, skills, and attributes of the respiratory therapist are critically necessary in acute care settings, the profession must move itself to a stronger position across the entire continuum of care of patients with acute and chronic cardiopulmonary diseases within the next several years to stay ahead of the curve of healthcare reform. In this paper, based on the 28th annual Philip Kittredge Memorial Lecture, I will examine the necessary strategies and values that the profession of respiratory care will need to successfully embrace to "think outside the box" and move the profession beyond the hospital walls for patient- and outcomes-focused, sustainable impact in the future healthcare delivery system. Key words: respiratory care; respiratory therapist; acute care; home care; chronic disease; disease management; reform. [Respir Care 2013; 58(8):1377-1385. ㅇ 2013 Daedalus Enterprises]
\end{abstract}

\section{Introduction}

Healthcare delivery in the United States is facing a crisis of epic proportions. Healthcare costs are growing faster than employee wages and the economy at large. Healthcare consumes $17 \%$ of the U.S. gross domestic product, and the U.S. consistently spends more on healthcare per capita than other developed countries. ${ }^{1}$ Healthcare costs currently exceed $\$ 9,000$ per capita and will increase at $6 \%$

Mr Myers is an Associate Executive Director of the American Association for Respiratory Care.

Mr Myers presented a version of this paper as the 28th Philip Kittredge Memorial Lecture at the 58th AARC Congress, held November 10-13, 2012, in New Orleans, Louisiana.

The author has disclosed no conflicts of interest. annually for the next decade. ${ }^{2}$ Despite this increased spending, the U.S. healthcare system still contains many issues and problems (Table 1). Regardless of the political or legal fallout of healthcare reform, those inside and outside healthcare believe the system is broken and must be fixed.

Recent data demonstrate that, while medical goods and services are generally viewed as basic necessities, the latest recession had a dramatic effect on their utilization, with U.S. healthcare spending growing at rates of $3.8 \%$ and $3.9 \%$ in 2009 and 2010, which is slower than any other

Correspondence: Timothy R Myers MBA RRT-NPS FAARC, American Association for Respiratory Care, 9425 N MacArthur Boulevard, Suite 100, Irving TX 75063. E-mail: myers@aarc.org.

DOI: $10.4187 /$ respcare. 02542 
Table 1. Current Health System Issues

Preventive services are under-used

Low adherence to proven-effective therapies for chronic diseases

Medical errors and safety problems remain too common, accounting

for many thousands of deaths and billions of dollars in healthcare costs

years during the 51-year history of the National Health Expenditure Accounts. ${ }^{3}$

\section{Healthcare Climate and Reform}

Despite the slowed healthcare-spending rate, most agree that the existing healthcare system and its associated cost must be reformed. The Patient Protection and Affordable Care Act, as amended by the Health Care and Education Reconciliation Act (enacted in March 2010), together known as the Affordable Care Act of 2010, introduced widespread changes to the healthcare system that are expected to affect both delivery and financing of care. ${ }^{4} \mathrm{Ta}-$ ble 2 highlights 4 critical areas that healthcare reform must focus and improve upon for a sustainable future.

Some of the numerous proposed changes would eliminate denials of coverage to those with preexisting conditions, and mandate healthcare insurance for all U.S. citizens and a pay for performance system. Depending on the list of conditions used to define preexisting conditions in each of the 5 estimates, the Government Accountability Office found that between 36 million and 122 million adults reported medical conditions that could result in a health insurer restricting coverage. This represents 20$66 \%$ of the adult population, with a midpoint estimate of about $32 \% .^{5}$

The restriction on preexisting conditions is important to the profession of respiratory care, as 2 of the top 10 conditions (Table 3) are asthma and COPD, which make up about $5 \%$ of the adult population and account for large national expenditures because of their prolonged disease course.

Chronic diseases not only result in a denial of insurance coverage, but also account for an increasing number of unscheduled physician and emergency department visits, and frequent hospitalizations. While the explosion of new medical technologies is frequently cited as the most common factor driving rising health costs, total cost is also a function of how many people are receiving treatment for a given condition. ${ }^{6}$ While cited from an older publication, Table 4 demonstrates the rise in treated disease prevalence over a 13-year period being a key factor accounting for the rise in healthcare spending, with pulmonary diseases ranking second of 15 highlighted in this publication.

A view of healthcare economic data reveals huge regional differences in healthcare costs, which tend to vary
Table 2. Critical Areas of Healthcare Reform Focus

Decrease the cost of healthcare

Improve the quality of care delivered

Evaluate effectiveness using outcome measures

Improve access and resource allocation

with the way the specific healthcare delivery market is organized, versus significant differences in the demonstrated clinical outcomes. More expensive areas are typically found to be highly competitive provider markets, with lots of competing services. In fact, more expensive areas show no better outcomes than the less expensive ones, while for some conditions they show worse outcomes.

These cost/outcomes data highlight the need to change the focus of the reimbursement model of U.S. healthcare. This type of data has led many to push for a pay-forperformance model of reimbursement. Hospitals have traditionally operated in a fee-for-service model, where they have been rewarded on the volume of services provided. Healthcare reform must mandate that the next step is to focus on cost and outcomes under a reimbursement model that does not reward volumes. This will drive hospitals and care to be more about efficiencies and patient-centered care than about volume of service.

A recent publication by Kruse and colleagues ${ }^{7}$ concluded that "pay-for-performance in the Centers for Medicare and Medicaid Services hospital demonstration project had no significant effect on hospital financials and Medicare payments to providers. As pay-for-performance extends to all hospitals under the Affordable Care Act, these results provide a better understanding of how costs of care change when quality improves under pay-for-performance." These types of demonstration projects, in addition to the recent focus on drastic changes in reimbursement models on patients readmitted to the hospital within 30 days, has led to a faster implementation phase of new models of care.

\section{Extending the Continuum: Outside the Hospital Walls}

U.S. healthcare is not focused on wellness or disease prevention; it is built for disease treatment. The current U.S. healthcare delivery system was developed in a time of technological advancements and advances in medical knowledge about infectious disease and medical interventions; it is not optimized for the efficient and effective day-to-day management of 21 st-century chronic diseases. This leaves today's model and its fragmented continuum unwieldy and lacking the necessary agility to properly manage chronic conditions.

Payers and consumers are moving toward healthcare provided in lower-cost settings and clinical differentiation 
Table 3. Estimates of Adults (Age 19-64) With Specified Conditions and Average Expenditures Associated With Each Condition for Those With Any Expenditures: 2009

\begin{tabular}{|c|c|c|c|c|c|c|}
\hline & $\begin{array}{l}\text { Estimated } \\
\text { Number }\end{array}$ & $\begin{array}{c}\text { Range, Based } \\
\text { on } 95 \% \text { CI }\end{array}$ & $\begin{array}{c}\text { Estimated } \\
(\%)\end{array}$ & $\begin{array}{c}\text { Range, Based } \\
\text { on } 95 \% \text { CI } \\
(\%)\end{array}$ & $\begin{array}{c}\text { Average } \\
\text { Annual } \\
\text { Expenditure } \\
(\$)\end{array}$ & $\begin{array}{c}\text { Maximum } \\
\text { Expenditure } \\
(\$)\end{array}$ \\
\hline Total population & $184,648,891$ & $176,372,785-192,924,998$ & 100 & & & \\
\hline Hypertension & $33,207,272$ & $31,145,377-35,269,167$ & 18.0 & $17.2-18.8$ & 650 & 61,540 \\
\hline Mental health disorders & $18,995,244$ & $17,516,845-20,473,642$ & 10.3 & $9.7-10.9$ & 1,757 & 98,058 \\
\hline Diabetes & $11,899,811$ & $11,007,195-12,792,427$ & 6.4 & $6.0-6.9$ & 1,782 & 66,007 \\
\hline Asthma & $10,047,807$ & $9,177,963-10,917,652$ & 5.4 & $5.0-5.9$ & 1,234 & 63,003 \\
\hline Arthritis & $9,518,122$ & $8,513,144-10,523,099$ & 5.2 & $4.7-5.7$ & 1,875 & 78,617 \\
\hline COPD & $9,091,824$ & $8,305,480-9,878,167$ & 4.9 & $4.5-5.3$ & 1,423 & 172,583 \\
\hline Cancer (excluding skin) & $4,150,263$ & $3,588,601-4,711,924$ & 2.3 & $2.0-2.5$ & 8,955 & 294,473 \\
\hline Rheumatoid arthritis & $3,041,838$ & $2,621,846-3,461,831$ & 1.7 & $1.4-1.9$ & 2,691 & 39,228 \\
\hline Heart attack (myocardial infarction) & $2,056,226$ & $1,678,883-2,433,568$ & 1.1 & $0.9-1.3$ & 4,013 & 53,666 \\
\hline Stroke & $1,291,310$ & $1,008,677-1,573,943$ & 0.7 & $0.6-0.9$ & 6,224 & 109,324 \\
\hline
\end{tabular}

Table 4. Changes in Nominal Health Care Spending on the 15 Most Costly Medical Conditions: 1987-2000

\begin{tabular}{|c|c|c|c|c|}
\hline \multirow[b]{2}{*}{ Condition } & \multirow{2}{*}{$\begin{array}{l}\text { Total Change in Spending } \\
\text { (millions \$) }\end{array}$} & \multicolumn{3}{|c|}{$\%$ Change in Spending Attributable to: } \\
\hline & & $\begin{array}{l}\text { Increase in Cost } \\
\text { Per Treated Case }\end{array}$ & $\begin{array}{l}\text { Rise in Treated } \\
\text { Prevalence }\end{array}$ & $\begin{array}{l}\text { Increased } \\
\text { Population }\end{array}$ \\
\hline Heart disease & $26,228.5$ & 68.6 & 1.1 & 30.3 \\
\hline Pulmonary conditions & $24,792.0$ & 37.5 & 41.9 & 20.6 \\
\hline Mental disorders & $24,503.3$ & 21.1 & 59.2 & 19.7 \\
\hline Cancer & $17,734.3$ & 41.9 & 27.4 & 30.7 \\
\hline Hypertension & $15,385.8$ & 59.8 & 18.9 & 21.3 \\
\hline Trauma & $14,596.6$ & 169.1 & -108.5 & 39.5 \\
\hline Cerebrovascular disease & $11,078.9$ & 20.8 & 60.3 & 18.9 \\
\hline Arthritis & $10,282.8$ & 44.3 & 31.6 & 24.1 \\
\hline Diabetes & $9,626.8$ & 23.6 & 49.8 & 26.6 \\
\hline Back problems & $9,486.4$ & 21.7 & 52.6 & 25.8 \\
\hline Skin disorders & $7,286.5$ & 54.8 & 22.0 & 23.2 \\
\hline Pneumonia & $7,203.8$ & 93.8 & -18.4 & 24.6 \\
\hline Infectious disease & $6,191.6$ & 95.2 & -17.5 & 22.3 \\
\hline Endocrine & $5,029.1$ & 28.0 & 43.4 & 28.6 \\
\hline Kidney & $3,231.4$ & 8.8 & 55.8 & 35.4 \\
\hline
\end{tabular}

$\overline{\text { (Data from reference } 6 .)}$

documented through patient outcomes. While there will always be a need for high-acuity, high-technology hospitals, the prevailing question is whether or not the majority of healthcare encounters can be facilitated in low-impact, lower-cost facilities, and even in the patient's own home. Creative, low-cost care models to deliver healthcare to Americans with underlying chronic conditions must be developed alongside wellness and prevention services offered to a healthy population. Advances in medical technology, clinical practice, and new integrated delivery models are the expected models of care in the future.
Current data estimate that approximately 9 million people per year are discharged from acute care facilities to some type of post-acute-care setting. This post-acute-care setting plays an increasing and critical role in transforming our delivery system into one that is more patient-centered, outcome-driven, and integrated. Table 5 provides examples of clinical integration between acute and post-acute care and how arrangements could yield important results.

As future technologies empower patients to take more control of their health and healthcare, hospitals are destined to downsize to the point where (unless they diver- 
Table 5. Post-Acute-Care Environments in the Continuum of Care

Long-term acute care (LTAC)

Patients with complex medical conditions requiring long-term complicated care

Skilled nursing facility

Short-term restorative care or medical care that is less complex.

Long-term "custodial" care

Rehabilitation/acute rehabilitation

Patients requiring shorter-term intensive rehabilitation

sify) they will provide only advanced trauma and critical care. The post-acute-care and medical home arenas will play an increasingly important role in the future healthcare model.

Long-term growth prospects supported by strong demographic trends and a substantial increase in the incidence of chronic disease must shift the focus of healthcare delivery. Post-acute and chronic care will increase in volume and complexity outside the hospital walls, in short-term and long-term care facilities. A key component will be to ensure collaboration among a diverse mix of healthcare providers and sites, to ensure high care quality, better-coordinated care transitions, and more efficient care delivery.

\section{Respiratory Care: Past and Present}

In 1943, Dr Albert Andrews wrote a monograph entitled Manual of Oxygen Therapy Techniques and proposed the formation of hospital departments for inhalation therapy. ${ }^{8}$ This was the humble beginning of the respiratory care profession. The effort was largely disjointed until Dr Edwin Levine, his students, and other interested doctors, nurses, and oxygen orderlies met at the University of Chicago Hospital to form the Inhalation Therapy Association in the summer of 1946.

In 1965, the U.S. Congress created Medicare under Title XVIII of the Social Security Act, to provide health insurance to people age 65 and older, regardless of income or medical history. Before Medicare's creation, only half of older adults had health insurance, with coverage often unavailable or unaffordable to the other half, because older adults had half as much income as younger people and paid nearly 3 times as much for health insurance. At this point the profession of respiratory care began to springboard within the hospital setting to provide a larger array of clinical services. Shortly thereafter, inhalation therapy schools were started, along with a formalized education and credentialing systems implemented.

In 1983 the Centers for Medicare and Medicaid Services adopted the Current Procedural Terminology (CPT) system and mandated that the code sets in the manual be used for all Medicare and Medicaid coding. The Centers for Medicare and Medicaid Services' influence on the commercial insurance companies, as well as individual and facility providers, allowed the CPT coding systems to become the standard across acute-care settings and ambulatory care areas. Respiratory care departments, leading to a "fee-for-service" system that ultimately rewarded volume-based care to generate higher levels of revenue, rapidly adopted utilization of CPT codes.

Around the same time as the implementation of CPT codes, diagnosis-related groups (DRGs) were also being implemented as a system to classify hospitalized patients, into 467 original groups. The primary intent of the DRGs was to identify the "products" that a hospital provides to patients. As the DRG system began to take hold and mature, it shifted to a system that determined how much Medicare would pay the hospital for each "product" at an agreed upon or fixed rate.

These major initiatives, as well as the onset of state licensure practice acts in the early 1990s, began to morph the profession of respiratory care into a "hybrid clinical role" with a rapidly growing scope of practice. The respiratory care profession continued to be able to bill for therapies, interventions, and services under the CPT coding system, with specificity to an area of service (ie, emergency department, in-patient areas, pulmonary function lab), like other allied health professions (eg, physical therapy, occupational therapy). The increasing scope of practice across the in-patient setting also increased the service-related, non-billable components of basic care and education to patients with cardiopulmonary disease that were not recognized under CPT codes but necessary to enhance and improve quality and care of patients in a manner similar to bedside nurses.

Around the year 2000, this increased scope of services provided, coupled with DRG-based reimbursement and managed care concepts and their associated reimbursement models, led to an evolving environment that changed many respiratory care departments from revenue-generators to "cost centers." This resulted in many inherent changes in the structure and delivery of respiratory care through many acute care facilities within the United States.

These dramatic changes led the American Association for Respiratory Care (AARC) to undertake and invest in an independent study of the profession, and generated 2 separate reports: the Muse report ${ }^{9}$ and the Lewin report. ${ }^{10}$

The Muse study was designed to look at the value of respiratory therapists (RTs) in skilled nursing facilities after the implementation of a prospective payment system, resulting in an estimated $75 \%$ of RTs being forced out of the skilled nursing facility environment. ${ }^{9}$ The Lewin report's purpose was to evaluate shifts in respiratory care practice in the context of the changing healthcare system and market dynamics. ${ }^{10}$ 


\section{Moving the Respiratory Care Profession Beyond the Hospital Walls}

Table 6. Key Findings From the American Association for Respiratory Care Commissioned Muse Report ${ }^{9}$ on the Skilled Nursing Facility Environment

1996 Health Care Financing Administration data showed 137,300 Medicare beneficiaries treated in skilled nursing facilities (SNFs) on an initial visit for diseases of the lung.

Approximately 73,540 (53.6\%) of beneficiaries received services from respiratory therapists (RTs) during initial SNF stay.

About $31 \%$ of beneficiaries not treated by RTs during initial SNF stay for lung disease subsequently required services in a hospital emergency room or out-patient setting.

Medicare spent 23\% more to treat beneficiaries who did not receive services from RTs, compared to those who did ( $\$ 2.7$ million vs $\$ 2.2$ million).

Fourteen percent of Medicare beneficiaries who did not receive RT services during initial SNF stay were readmitted to an SNF

3.6-day shorter average stay for RT-treated SNF beneficiaries saved Medicare \$97.9 million.

Shorter stay of the RT-treated group attributed to RT expertise and efficacy of clinical interventions.

During initial SNF stay, mortality among beneficiaries not treated by RTs was 8.3 per 1,000 , compared to 4.8 per 1,000 among those treated by RTs (ie, $42 \%$ lower mortality among RT-treated beneficiaries).

Mortality 14\% lower than for RT-treated beneficiaries with second visit contact.

The Muse report was initiated to analyze the clinical outcomes and financial ramifications of patients who received respiratory care services in skilled nursing facilities from RTs, compared to patients who received these same services from other care providers. The analysis found that Medicare beneficiaries treated by RTs had better outcomes and lower costs then those not treated by RTs. A multivariate analysis and subsequent analyses further showed that these findings were true regardless of age, sex, comorbidities, or the incidence of stroke. Key findings from the Muse report can be found summarized in Table $6 .{ }^{9}$ Despite these findings, the growth of RTs into post-acutecare environments was and continues to be sporadic and variable across the United States.

The Lewin report's executive summary synthesized important findings from the 3 separate components (literature review, AARC membership survey, and structured interviews and case studies) analyzed. The findings from each of the 3 components were consistent, cohesive and complementary, yielding a number of important insights and recommendations for the profession as it transitions in the changing healthcare environment. Those key findings are identified in Table 7.10

When the distribution of the RT workforce is assessed today, retrospective analysis of these 2 reports shows that the respiratory care profession was able to meet the rapidly changing environment within the hospital walls. But the loss of reimbursement in a fee-for-service model and the overall lack of identified clinical or financial outcomes
Table 7. Key Findings From the American Association for Respiratory Care Commissioned Lewin Report ${ }^{10}$

Respiratory therapists (RTs) are highly valued for specialized clinical skills

The importance of clinical skills is emphasized throughout the report, but other skills were found to be an important and necessary supplement to a foundation of specialized clinical knowledge.

There was substantial consistency across settings in terms of the importance of many skills, but some differences in desired skill sets between practice settings.

RTs have started to take advantage of emerging opportunities by entering new areas of clinical practice.

RTs must adapt as jobs shift from acute care settings to other care settings.

RTs are viewed as cost-effective for specific tasks and settings, but additional studies must document overall RT cost-effectiveness.

Reimbursement policy has important implications for perceptions about RTs, particularly in the long-term-care and home health settings.

RTs are increasingly performing "managed care" duties, but their value in these roles is not well documented.

Some RTs have demonstrated success under managed care models, but additional evidence must be documented to succeed in nontraditional environments.

alluded to in the Lewin report have left the majority of the profession and its practitioners concentrated only in the hospital setting. This workforce distribution currently leaves the profession out of optimal position to provide the care of patients with respiratory diseases, in both wellness and exacerbations, across the continuum of care.

A paper published in 2005 by Merendino and Wissing ${ }^{11}$ highlighted the continued need to more equally distribute the respiratory care workforce to meet the shifting dynamics from one of acute respiratory disease treatment to that of chronic disease management. The authors stated that "the profession is gradually moving beyond the traditional acute-care facilities into extended care, sleep medicine, disease management, patient transport, and even fields beyond healthcare delivery, such as education and research. RTs will survive in these changing times if they possess the ability to recognize change as an opportunity for growth." The concluding comments from this paper described the need for a paradigm shift: "As the baby boomer generation ages, and the incidence of chronic illness increases, RTs will be in even greater demand."

\section{The Future of Respiratory Care}

The drive toward healthcare reform, coupled with increases in patient coverage; increasing need for chronic disease management across the continuum of care; and the focus on improving the access, quality, and safety of care provided to these patients, has left much of the healthcare system in a rapid transition phase. The profession of re- 


\section{Moving the Respiratory Care Profession Beyond the Hospital Walls}

Table 8. Content Outline of the 3 AARC Task Force Conferences on the Future of the Respiratory Care Profession ${ }^{12-14}$

\begin{tabular}{ll}
\hline \hline Conference & \multicolumn{1}{c}{ Objectives } \\
\hline 1 & $\begin{array}{c}\text { Identify the emerging values of the United States } \\
\text { healthcare delivery system. } \\
\text { Define potential new roles and responsibilities of } \\
\text { respiratory therapists (RTs) in } 2015 \text { and } \\
\text { beyond. } \\
\text { Identify the skills, knowledge, attributes, } \\
\text { education, and competency documentation } \\
\text { RTs need for the new roles and } \\
\text { responsibilities. } \\
\text { Determine how to prepare RTs for the new roles } \\
\text { and responsibilities, with minimal impact on } \\
\text { the work force. }\end{array}$ \\
\hline
\end{tabular}

spiratory care is no different than other healthcare clinicians and providers, with one major caveat. Data from the AARC's human resources survey in 2009 documents that approximately $75 \%$ of the respiratory care workforce is currently employed in the acute care hospital and education sectors; this places the profession at a severe disadvantage in providing their necessary skills, knowledge, and attributes for patients with chronic respiratory disease across the continuum of care.

A decade ago, the AARC's Board of Directors authorized a 3-series set of conferences titled "Respiratory Care: 2015 and Beyond," to define the role of the RT in light of future healthcare trends and to determine an effective strategy for achieving success as a profession, based on the needs of the respiratory care patient and the evolving healthcare system. These conferences rolled out over a number of subsequent years, and a summary of their proceedings was published in Respiratory CARE. ${ }^{12-14}$ Table 8 provides a summary of the conferences objectives. ${ }^{12}$

In the second AARC conference in the "2015 and Beyond" series, the participants identified a grouping of respiratory care competencies that would be necessary for future graduates and those practicing in the profession. The areas of competencies were discussed in great detail in the paper by Barnes et al and are listed in Table 9.13 While some of these areas fall under the scope of practice of the profession as it has grown over the past 6 decades, many of these competency areas are not practiced in substantial depth and breadth at this point but are targeted to fit into the future landscape of the healthcare system. The necessary growth into the post-acute-care environment in greater numbers has already been highlighted here, so I will not revisit that specific area, but will focus on the needs of wellness and prevention programs, chronic disease management, and the role of the RT as a "physician extender."

Wellness and prevention are areas in which RTs are currently under-utilized, due to their lack of presence in
Table 9. Educating the Future Respiratory Therapist Workforce: Required Competencies ${ }^{13}$

Patient assessment

Evidence-based medicine and protocols

Disease management

Therapeutics

Emergency and critical care

Diagnostics

Leadership

the ambulatory care settings in substantial numbers. The concept of wellness and disease prevention can be a large, undefined one, based on perception, but in theory would incorporate the use of preventive medicine and vaccination, and the discernment of risk factors that might make someone more prone to ailment. Respiratory diseases fit into this strategy and are identified as such in the Department of Health and Human Services Healthy People 2020 initiatives.

Areas that are commonly thought of as wellness and preventive services may include smoking cessation, control of asthma and COPD exacerbations, and proper prescribing and use of inhaled medications for chronic respiratory diseases, to name a few. The RT has in the past and can continue to play an important role in smoking cessation programs, as they are uniquely positioned to identify patients in a variety of care settings in addition to being well versed professionals with expert knowledge in lung physiology.

$\mathrm{RT}$ involvement in smoking cessation is not a new or novel concept to the profession. In 2000, Stevens et al published a study that evaluated the implementation and effectiveness of a smoking cessation intervention program when delivered by RTs chosen from the regular hospital staff. ${ }^{15}$ The study recommended implementation of hospital-based smoking-cessation counseling by professional counselors whose primary responsibility was to deliver the intervention. Recommendations for future research and for innovative ways to reach hospitalized smokers who are not receiving intervention were also discussed.

Marlow and Stoller ${ }^{16}$ introduce the concept of RTs as being instrumental in smoking cessation by stating, "since RTs interact with smokers frequently, we believe it is particularly important for RTs to show leadership in implementing smoking cessation." A symposium lecture that was later published by Goodfellow and Waugh speculated on the future role of the RT in serving as a smoking cessation counselor. ${ }^{17}$ The authors stated, "As changes are occurring in our practices because of economic pressures, this is a positive change we can make for our patients and our workplaces. We are in a unique position to offer tobacco-use-prevention advice and to provide information on smoking-cessation resources to our patients." 
A more recent study, by Tremblay et al, from Québec, Canada seeks to assess if smoking-cessation counseling practices and related psychosocial characteristics among RTs improved between 2005 and 2010.18 The authors surveyed and collected data from mailed, self-report questionnaires in 2005 and in 2010, in random independent samples of active licensed RTs. The authors concluded that although the proportion of RTs trained in smokingcessation counseling during and after studies increased between 2005 and 2010 (from 3\% to 14\%, and from 17\% to $29 \%$, respectively), sustained efforts are needed to increase the number of trained RTs so that this translates into positive observable changes in counseling practices.

The area of patient education, assessment, and review of appropriate medication delivery for patients with chronic respiratory diseases is an area that overlaps wellness and prevention strategies with those of chronic disease management. There a number of studies that document the proficiencies of the RT as the key stakeholder in understanding the variety of devices and specific techniques necessary for appropriate use of inhaled medications. In 2004, Minai et al published ${ }^{19}$ a study in which physicians and RTs collaborated to improve metered-dose inhaler (MDI) technique and outcomes among asthmatic children. In this study, clinicians demonstrated and reinforced correct MDI technique with every patient visit, using a standardized format. The 3-year study demonstrated that in this clinical trial, asthmatic children showed sustained improvement in MDI technique, and some of the patients improved in pulmonary function and overall asthma severity score.

A more recent trial by Song et $\mathrm{al}^{20}$ was conducted to look at the potential benefit of an RT giving instruction on the use of MDIs to 58 hospitalized patients with obstructive lung disease. The baseline error rate was 6.72 (out of 15 possible) errors per patient, and improved to 2.43 errors per patient after RT-provided instruction $(P<.001)$. The authors concluded that instruction of hospitalized patients with obstructive lung disease by an RT improves their correct use of MDIs and increases their use of spacers while in the hospital.

One could argue that any healthcare clinician could and should be able to instruct patients on correct inhaler technique, and that the RT was just the intervention in the Song trial, and not necessarily the "difference maker." In a study of healthcare clinicians" knowledge and abilities to provide proper MDI technique, Interiano and Guntupalli21 evaluated the proficiency of healthcare providers and patients in the proper use of MDIs, a study that included house staff (physicians), nurses, and RTs. The study's key findings are highlighted in Table 10. Interiano and Guntupalli went on to encourage "the use of RTs in the outpatient setting, since they were the most proficient among all the healthcare providers in the proper use of MDIs."
Table 10. Main Results From a Study of Metered-Dose Inhaler Knowledge and Technique ${ }^{21}$

Many patients have a poor understanding of metered-dose inhaler (MDI) technique

House staff and nurses were also less proficient in proper MDI use Respiratory therapists were the most knowledgeable providers on MDI use

The expertise of the RT as the most appropriate healthcare clinician to demonstrate and provide correct technique is not related solely to the MDI. Chopra et $\mathrm{al}^{22}$ conducted a study to determine whether introduction of newer "easy to use" dry powder inhalers, such as budesonide (Turbuhaler) and salmeterol (Diskus), would result in improvement in medical personnel's knowledge of their proper use. The study's results documented that the mean percentage demonstration scores of different medical personnel for all 3 devices taken together were: RTs (81.6\%), primary care physicians $(77.7 \%)$, pharmacists $(57.7 \%)$, registered nurses $(54.4 \%)$, and medical residents $(53.8 \%)$.

Patient education on inhaled medications and delivery device knowledge transitions nicely to the concept of the RT as a disease manager for patients with chronic respiratory diseases. In a Journal conference publication, Kallstrom and Myers ${ }^{22}$ highlighted the concept of the RT as an asthma disease manager:

The role of the RT is expanding with the growing
acceptance and use of the disease-management par-
adigm for managing chronic diseases. RTs are key
members of the asthma disease-management team,
in acute-care settings, patients' homes, out-patient
clinics, emergency departments, and in the commu-
nity. Utilizing RTs as disease managers allows pa-
tients to be treated faster and more appropriately,
discharged to home sooner, and decreases hospital
admissions.

This concept of the RT as disease manager was nicely demonstrated recently, not with asthma patients, but with COPD patients, in a study by Rice and colleagues. ${ }^{24}$ This study sought to determine whether a simplified disease management program conducted by RTs within a multicenter, Veteran Affairs hospital setting, could reduce hospital admissions and emergency department visits due to COPD. After 1 year there was a significant reduction in the mean cumulative frequency of COPD-related hospitalizations and emergency department visits $(P<.001)$, reduced hospitalizations for cardiac or pulmonary conditions other than COPD by $49 \%$, hospitalizations for all causes by $28 \%$, and emergency department visits for all causes by $27 \%$ ( $P<.05$ for all). Other significant outcomes were an improved St George's Respiratory Questionnaire score, 
Table 11. Data From the American Association for Respiratory Care 2009 Human Resources Survey: Procedures Being Performed by Respiratory Therapists

\begin{tabular}{|c|c|c|c|}
\hline & Frequency & $\begin{array}{l}\text { Percent } \\
\text { of } \\
\text { Cases }\end{array}$ & $\begin{array}{l}\text { Projected Number of } \\
\text { Active Respiratory } \\
\text { Therapists in the } \\
\text { Population }\end{array}$ \\
\hline Bronchoscopy & 1,353 & 57.2 & 65,650 \\
\hline Arterial line insertion/maintenance & 547 & 23.1 & 26,541 \\
\hline Intravenous line insertion/maintenance & 239 & 10.1 & 11,597 \\
\hline Anesthesia in the operating room & 50 & 2.1 & 2,426 \\
\hline Emergency intubation & 1,760 & 74.4 & 85,398 \\
\hline Conscious sedation & 746 & 31.5 & 36,197 \\
\hline Sleep studies & 466 & 19.7 & 22,611 \\
\hline Invasive cardiology & 134 & 5.7 & 6,502 \\
\hline Noninvasive cardiology & 723 & 30.5 & 35,081 \\
\hline Patient transport outside the facility & 904 & 38.3 & 43,864 \\
\hline Physiologic monitoring in the ICU & 831 & 35.2 & 40,321 \\
\hline Hyperbaric medicine & 124 & 5.3 & 6,017 \\
\hline Discharge planning/patient instruction & 1,258 & 53.2 & 61,040 \\
\hline Other & 345 & 14.6 & 16,740 \\
\hline
\end{tabular}

improved prescribing practices for prednisone and antibiotics $(P<.001$ for all), and day's supply of long-acting controller medications $(P=.008)$ for COPD patients receiving disease management by RT after discharge from the Veterans Affairs hospital system.

An expanded role of the RT for patients with chronic respiratory diseases seems to be an evolving concept supported with growing evidence based on the knowledge, skills, and attributes of the RT, and is within the scope of respiratory practice. But what of expanding the use of RTs into other areas, perhaps as physician extenders?

In fact, the AARC's 2009 human resources survey demonstrates evidence of the continuing growth of the practice scope of the RT in a number of areas not highlighted in core competencies from the 2015 conferences listed in Table 9. Table 11 provides a high-level perspective of these "non-traditional" areas and the number of procedures reported by the survey sample, as well as the percentage of cases and potential RTs involved in these growing areas of service and care. These areas, as well as others not listed here or potential new ones identified in the future, lead to the possibility of RTs serving as physician extenders in the acute, post-acute, and ambulatory settings.

Two recent publications demonstrating the potential of RTs in these growing roles may serve as food for thought and consideration as we move toward the future healthcare setting and its delivery of care. A study by Tearl and colleagues ${ }^{25}$ evaluated the role of a dedicated RT coordinator to provide education and coordination of discharge planning for 74 respiratory-technology-dependent pediatric patients. The authors concluded that a dedicated RT discharge coordinator, facilitating early family identification, home-care equipment application, and institution of family education, allowed ample time for family preparation and eased the transition to the home environment. It also assured that training was accomplished in a consistent and thorough fashion and that communication among all parties was timely and accurate.

Zakrzewski and colleagues, in an operating room setting in a Canadian facility, conducted a study that perhaps highlights the potential of RTs in other areas of the healthcare environment. ${ }^{26}$ This prospective, observational cohort study reevaluated the safety and practicality of registered RTs (RRTs) providing monitored anesthesia care for 15,440 consecutive patients undergoing phacoemulsification cataract surgery. The study's results offered no serious perioperative medical complications leading to death, endotracheal intubation, or postoperative hospitalization. A total of 395 cases $(2.6 \%)$ required anesthesia intervention, with $257(1.7 \%)$ occurring preoperatively, $140(0.91 \%)$ occurring intraoperatively, and 5 occurring $(0.03 \%)$ postoperatively. The authors concluded that allowing RRTs to provide monitored anesthesia care during cataract surgery, with an anesthesiologist available as required, seems to be both safe (no serious medical complications in 15,440 cases) and practical (anesthesiology intervention rate of 2.6\%).

\section{Summary}

Expansion and growth outside the traditional acute care setting are vitally necessary for the future of the RT in the healthcare setting as it continues to evolve. In an era of healthcare reform focused on reduction in cost, built-in quality and safety, and a more efficient, collaborative continuum of care, the RT needs to be poised to follow the patient with chronic respiratory conditions across the en- 


\section{Moving the Respiratory Care Profession Beyond the Hospital Walls}

tire spectrum of care, including wellness and prevention, disease management practices and principles, and exacerbations.

The RT provides a unique and necessary set of skills, knowledge, and attributes to the healthcare environment that offer a diverse opportunity to maximize care in a safe, efficient, and cost-effective manner. The data that support this role in the acute care setting have been strongly documented over the past 20-25 years through numerous publications and studies. While the data are not as strong in the post-acute or ambulatory care settings, the current dysfunction in the continuum of care for patients with chronic respiratory disease presents an opportunity for the RT of the future.

To every person there comes in life that special moment when one is tapped on the shoulder and offered the chance to do a very special thing. What a tragedy if that moment finds you unprepared or unqualified for the work which would be your finest hour.

\section{- Sir Winston Churchill}

\section{REFERENCES}

1. Davis K, Schoen C, Sremikis K. Mirror, mirror on the wall: how the performance of the US health care system compares internationally: 2010 update. New York: The Commonwealth Fund; 2010.

2. Centers for Medicare and Medicaid Services. National health expenditure projections 2009-2019. https://www.cms.gov/ResearchStatistics-Data-and-Systems/Statistics-Trends-and-Reports/National HealthExpendData/downloads/NHEProjections2009to2019.pdf. Accessed May 23, 2013.

3. Martin AB, Lassman D, Washington B, Catlin A; National Health Expenditure Accounts Team. Growth in US health spending remained slow in 2010; health share of gross domestic product was unchanged from 2009. Health Aff (Millwood) 2012;31(1):208-219.

4. Holahan J, McMorrow S. Medicare and Medicaid spending trends and the deficit debate. N Engl J Med 2012;367(5):393-395.

5. United States Government Accountability Office. Private health insurance: estimates of individuals with pre-existing conditions range from 36 million to 122 million. Washington DC: GAO; 2012: GAO-12-439. http://www.gao.gov/assets/590/589618.pdf. Accessed May 23, 2013.

6. Thorpe KE, Florence CS, Joski P. Which medical conditions account for the rise in health care spending? Health Aff (Millwood) 2004; Suppl Web Exclusives:W4-437-445.

7. Kruse GB, Polsky D, Stuart EA, Werner RA. The impact on hospital pay-for-performance on hospital and medicare costs. Health Serv Res 2012;47(6):2118-2136.

8. Andrews AH. Manual of oxygen therapy techniques, including carbon dioxide, helium and water vapor. Chicago: The Year Book Publishers, 1943.
9. Muse \& Associates. Executive summary: a comparison of medicare nursing home residents who receive services from a respiratory therapist with those who do not. August 1999. http://www.aarc.org/ resources/muse/. Accessed May 23, 2013.

10. American Association for Respiratory Care; The Lewin Group. Executive summary: respiratory care practitioners in an evolving health care environment. 1997. http://www.aarc.org/advocacy/resources/ lewin_report/executive_summary.html. Accessed May 23, 2013.

11. Merendino D, Wissing DR. New roles for respiratory therapists: expanding the scope of practice. Respir Care Clin N Am 2005;11(3): 543-555.

12. Kacmarek RM, Durbin CG Jr, Barnes TA, Kaegler WV, Walton JR, O'Neil EH. Creating a vision for respiratory care in 2015 and beyond. Respir Care 2009;54(3):375-389.

13. Barnes TA, Gale DD, Kacmarek RM, Kaegler WV. Competencies needed by graduate respiratory therapists in 2015 and beyond. Respir Care 2010;55(5):601-616.

14. Barnes TA, Kacmarek RM, Kaegler WV, Morris MJ, Durbin CG Jr. Transitioning the respiratory therapy workforce for 2015 and beyond. Respir Care 2011;56(5):681-690.

15. Stevens VJ, Glasow RE, Hollis JF, Mount K. Implementation and effectiveness of a brief smoking-cessation intervention for hospital patients. Med Care 2000;38(5):451-459.

16. Marlow SP, Stoller JK. Smoking cessation. Respir Care 2003;48(12): 1238-1254.

17. Goodfellow GT, Waugh JB. Tobacco treatment and prevention: what works and why? Respir Care 2009;54(8):1082-1090.

18. Tremblay M, O'Loughlin J, Comtois D. Respiratory therapists' smoking cessation counseling practices: a comparison between 2005 and 2010. Respir Care 2013;58(8):1299-1306

19. Minai BA, Martin JE, Cohn RC. Results of a physician and respiratory therapist collaborative effort to improve long-term metereddose inhaler technique in a pediatric asthma clinic. Respir Care 2004;49(6):600-605.

20. Song WS, Mullon J, Regan NA, Roth BJ. Instruction of hospitalized patients by respiratory therapists on metered-dose inhaler use leads to decrease in patient errors. Respir Care 2005;50(8):1040-1045.

21. Interiano B, Guntupalli KK. Metered-dose inhalers do health care providers know what to teach? Arch Intern Med 1993;153(1):81-85.

22. Chopra N, Oprescu N, Fask A, Oppenheimer J. Does introduction of new "easy to use" inhalational devices improve medical personnel's knowledge of their proper use? Ann Allergy Asthma Immunol 2002; 88(4):395-400.

23. Kallstrom TJ, Myers TR. Asthma disease management and the respiratory therapist. Respir Care 2008;53(6):770-776.

24. Rice KL, Dewan N, Bloomfied HE, Grill J, Schult TM, Nelson DB, et al. Disease management program for chronic obstructive pulmonary disease: a randomized controlled trial. Am J Respir Crit Care Med 2010;182(7):890-896

25. Tearl DK, Cox TJ, Hertzog JH. Hospital discharge of respiratorytechnology-dependent children: role of a dedicated respiratory care discharge coordinator. Respir Care 2006;51(7):744-749.

26. Zakrzewski PA, Banashkevich AV, Friel T, Braga-Mele R. Monitored anesthesia care by registered respiratory therapists during cataract surgery: an update. Ophthalmology 2010;117(5):897-902. 